\title{
Time trends of morning and evening macronutrient intakes in children and adolescents
}

\author{
S. Roßbach, T. Diederichs, K. Bolzenius, A. E. Buyken and U. Alexy \\ Institute of Nutritional and Food Sciences - Nutritional Epidemiology, University of Bonn, DONALD Study, \\ Dortmund, Germany
}

The role of nutrition for the circadian clock system has recently received increasing recognition. On the one hand, food metabolism and energy homeostasis are influenced by the circadian clock. On the other hand, food intake, time of meals and specific nutrients themselves are potential zeitgeber and are also able to entrain the clock ${ }^{(1)}$. In addition, disruptions of circadian eating pattern are discussed to affect health, e.g. the development of obesity and type 2 diabetes ${ }^{(2)}$. However, little is known about circadian eating pattern in children and adolescents. Therefore, our objective was to describe time trends of morning and evening macronutrient intakes as characteristics of circadian eating pattern in 3-18-year-old participants of the German DONALD (Dortmund Nutritional Anthropometric Longitudinally Designed) study ${ }^{(3)}$.

Overall, 9757 3-day weighed dietary records from 1246 participants (629 boys, 617 girls) collected between 1985 and 2014 were available. Morning intake was defined as all energy intakes before $11 \mathrm{am}$, evening intake as all intakes after $6 \mathrm{pm}$, respectively. Time trends of macronutrient intakes (as percentage of morning/evening energy intake $(\% \mathrm{E})$ ) were analyzed using polynomial mixed-effects regression models. Energy intake, body weight status and family as well as socio economic characteristics were considered as potentially confounding factors.

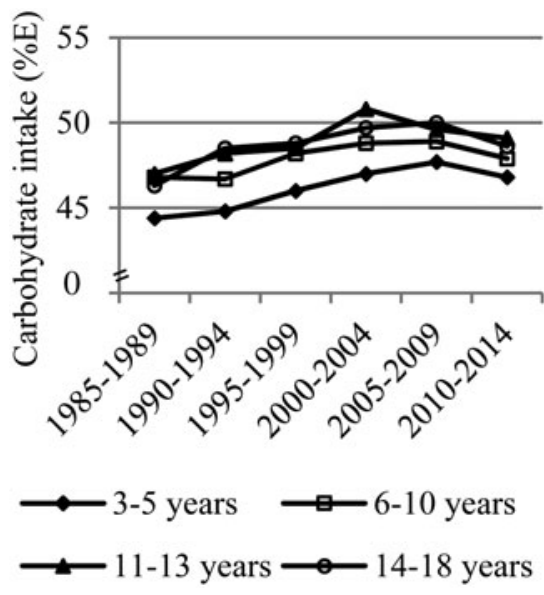

Fig. 1. Adjusted carbohydrate intake in the evening

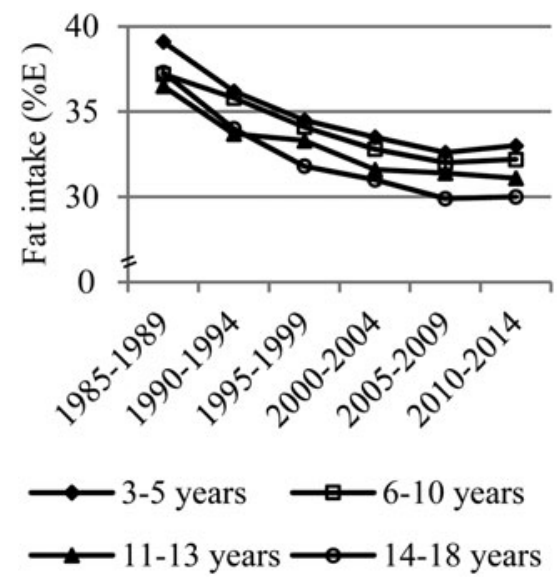

Fig. 2. Adjusted fat intake in the evening

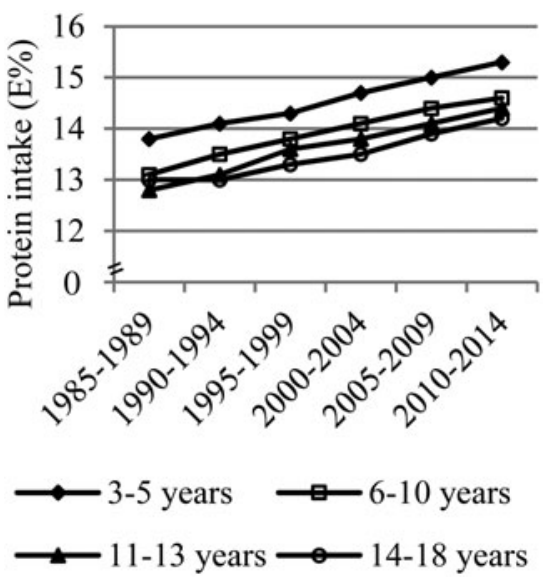

Fig. 3. Adjusted protein intake in the evening, girls

Evening carbohydrate intake increased until the early 2000s and leveled off or decreased thereafter (quadratic and cubic trend, $\mathrm{p}<0.01$ ) (Fig. 1). By contrast, evening fat intake decreased until the late 2000s (quadratic and cubic trend, $p<0.01)($ Fig. 2). Protein intake increased continuously in girls (linear trend, $\mathrm{p}<0.0001$ ) (Fig. 3) and in boys (quadratic trend, $\mathrm{p}=0.03$; data not shown). Similar time trends were observed for macronutrient intakes in the morning (data not shown).In conclusion, the daytime specific time trends for carbohydrate and fat intakes confirm results from previous studies on time trends in overall daily macronutrient intakes. Interestingly, protein intakes in the morning and in the evening increased continuously over the study period. Relevance of food group intakes for the observed time trends should be further investigated.

1. Froy O (2007) The relationship between nutrition and circadian rhythms in mammals. Front Neuroendocrinol 28(2-3), 61-71.

2. Garaulet M, Madrid JA (2010) Chronobiological aspects of nutrition, metabolic syndrome and obesity. Adv Drug Deliv Rev 62(9-10), 967-978.

3. Kroke A, Manz F, Kersting M et al. (2004) The DONALD Study. History, current status and future perspectives. Eur J Nutr 43, 45-54. 